\title{
First detection of the $k d r$ mutation (L1014F) in the plague vector Xenopsylla cheopis (Siphonaptera: Pulicidae)
}

\author{
Nian Liu ${ }^{1}$, Xiangyang Feng ${ }^{2}$, Mei Li ${ }^{1}$ and Xinghui Qiu ${ }^{1 *}$ (I)
}

\begin{abstract}
Background: The oriental rat flea, Xenopsylla cheopis, is the most efficient vector of the plague. Pyrethroid insecticides such as cypermethrin, cyhalothrin and deltamethrin have been often used to limit plague transmission via controlling the vector during outbreaks. However, this strategy is threatened by the development of insecticide resistance. Understanding the mechanisms underlying pyrethroid resistance is the prerequisite for successful flea control.

Methods: Partial DNA sequences of $X$. cheopis voltage gated sodium channel (VGSC) gene were amplified from a total of 111 individuals, collected from a natural plague epidemic foci in Baise City, Guangxi Zhuang Autonomous Region of China. These DNA fragments were sequenced. The frequency and distribution of $k d r$ mutations were assessed in four $X$. cheopis populations. The origin of $k d r$ mutations was investigated by phylogenetic and network analysis.

Results: The classical knockdown resistance ( $k d r)$ mutation (L1014F) was detected in four field populations at frequencies ranging between 0.021-0.241. The mutant homozygote was observed only in one of the four populations. Seven haplotypes were identified, with two of them carrying the resistance L1014F mutation. Phylogenetic tree and network analysis indicated that the L1014F allele was not singly originated. Based on polymerase chain reaction restriction fragment length polymorphism (PCR-RFLP) profiling, an easy-to-use and accurate molecular assay for screening individual fleas for the L1014F mutation was developed.

Conclusions: To our knowledge, this work represents the first report of the L1014F mutation in the plague vector $X$. cheopis. The incidence of the L1014F allele highlights the need of further studies on the phenotypic effect of this mutation in this plague vector. Early detection and monitoring of insecticide resistance is suggested in order to make effective control strategies in case of plague outbreaks in this region.
\end{abstract}

Keywords: Xenopsylla cheopis, Voltage-gated sodium channel, Knockdown resistance, PCR-RFLP

\section{Background}

The bubonic plague, caused by the bacterium Yersinia pestis, is a highly transmissible zoonotic disease. This disease is re-emerging with outbreaks occurring in many regions of the World [1]; 3248 cases were reported worldwide from 2010 to 2015, including 584 deaths [2].

\footnotetext{
*Correspondence: qiuxh@ioz.ac.cn

1 State Key Laboratory of Integrated Management of Pest Insects and Rodents, Institute of Zoology, Chinese Academy of Sciences, Beijing 100101, China

Full list of author information is available at the end of the article
}

The transmission of plague from rodents to humans is primarily caused by flea bites. The most efficient vector of the plague bacterium from rodents to humans is the flea species Xenopsylla cheopis; therefore, it has attracted increasing attention [3].

Plague remains an important health problem in China with 12 natural plague epidemic foci covering an area of $143.45 \mathrm{~km}^{2}$ in 19 provinces $[4,5]$. Human plague once occurred in the region along the Tian-Sheng-Qiao Reservoir during 2000 to 2003 [5]. The Tian-Sheng-Qiao Reservoir was built in 1987, and water impoundment began from 1997 to 2000 . This reservoir is located in the 
border region of three provinces (Guizhou, Guangxi and Yunnan), with a capacity of 10.3 billion $\mathrm{m}^{3}$. An epidemiological study documented that the outbreak of human bubonic plague was resulted from flea (X. cheopis) bites through rat-flea-human circulation [6]. The primary hosts of $X$. cheopis are Rattus flavipectus and Rattus norvegicus in this region $[7,8]$. Since the plague outbreak, control of rats has been conducted twice a year (in spring and autumn) since 2002, usually followed by flea controls via spraying pyrethroids such as cypermethrin, cyhalothrin and deltamethrin on wall surface or ground surface [9].

Intensive use of insecticides can theoretically induce the development of resistance, ultimately leading to control failures. Xenopsylla cheopis populations were reported to be resistant to different classes of insecticides $[3,10,11]$. For example, 32 of 36 populations of $X$. cheopis were found to be resistant to deltamethrin in Madagascar [3]. However, the genetic basis underlying insecticide resistance in these populations remains unknown.

The voltage gated sodium channels (VGSC) are the primary target of pyrethroids in insects. VGSC mutationmediated knockdown resistance $(k d r)$ is the common and main cause of resistance to pyrethroids in insects [12-15]. Previous studies have documented more than 50 mutations or combinations of mutations associated with $k d r$ in various arthropods [12], with the L1014F mutation in IIS6 being the first mutation that was detected and confirmed as a cause of $k d r$ [13]. The conserved L1014F mutation was also characterized in the cat flea Ctenocephalides felis [14], and in the human flea Pulex irritans [15]. The present study aimed to investigate possible pyrethroid resistance-conferring genetic mutations in the voltage gated sodium channel, and to assess the geographical distribution of resistant genotypes in $X$. cheopis populations. Based on our results, a rapid diagnostic assay to detect the $k d r$ mutation was established.

\section{Methods \\ Flea samples}

Fleas ( $X$. cheopis) were collected in four different sites near the Tian-Sheng-Qiao Reservoir in Baise of Guangxi Province during 2017 and 2018, where plague outbreak occurred during 2000-2003 and pyrethroids have been extensively applied since then. Brief information about the sampling locations and dates is provided in Table 1. Flea samples were obtained according to the method of Nong et al. [9]. Briefly, live rats were trapped using randomly placed trap cages (100 cages/site), and brought to the laboratory; the trapped rat was placed into a sack filled with ether. Fleas were collected, classified morphologically, and stored in $100 \%$ alcohol at $4{ }^{\circ} \mathrm{C}$.
Table 1 Brief information for Xenopsylla cheopis collection in Baise of Guangxi, China

\begin{tabular}{|c|c|c|c|}
\hline Site & Location & Coordinate & Date \\
\hline 1 & Yongle, Youjiang County & $106^{\circ} 37^{\prime} 12^{\prime \prime} \mathrm{E}, 23^{\circ} 59^{\prime} 24^{\prime \prime} \mathrm{N}$ & October 2017 \\
\hline 2 & $\begin{array}{l}\text { Wangdian, Youjiang } \\
\text { County }\end{array}$ & $106^{\circ} 21^{\prime} 4^{\prime \prime} \mathrm{E}, 24^{\circ} 11^{\prime} 24^{\prime \prime} \mathrm{N}$ & October 2017 \\
\hline 3 & Gebu, Longlin County & $105^{\circ} 2^{\prime} 24^{\prime \prime} \mathrm{E}, 24^{\circ} 47^{\prime} 24^{\prime \prime} \mathrm{N}$ & June 2018 \\
\hline 4 & Bada, Xilin County & $105^{\circ} 6^{\prime} 3^{\prime \prime} \mathrm{E}, 24^{\circ} 29^{\prime} 24^{\prime \prime} \mathrm{N}$ & April 2018 \\
\hline
\end{tabular}

Extraction of genomic DNA and amplification of XC-VGSC gene fragments

Genomic DNA of individual fleas was isolated by the method of Rinkevich et al. [16]. Primers (Xchvgsc-F: 5'-GTG CCT TGG GTA ATC TAA CGT-3' and Xchvgsc-R: 5'-CGA CAA GAG CAA CGC CAA G-3') were designed based on the partial DNA sequence of $X$. cheopis para-type voltage-gated sodium channel-like gene (GenBank: JQ894869.1), and used to amplify gene fragments ( $440 \mathrm{bp}$ ) containing codon 1014 (Musca domestica numbering) within the domain II region of insect para sodium channel. The reaction mixture consisted of $12.5 \mu \mathrm{l}$ of $2 \times$ SuperHiFi PCR Master Mix (DAKEWE Biotech, Shenzhen, China), each primer $5 \mu \mathrm{M}, 75-150 \mathrm{ng}$ DNA template, and $d_{d d} \mathrm{H}_{2} \mathrm{O}$ up to $25 \mu \mathrm{l}$. Reactions were programmed as $95{ }^{\circ} \mathrm{C}$ for $3 \mathrm{~min}, 42$ cycles of $94{ }^{\circ} \mathrm{C}$ for $25 \mathrm{~s}, 55^{\circ} \mathrm{C}$ for $25 \mathrm{~s}, 68{ }^{\circ} \mathrm{C}$ for $30 \mathrm{~s}$, and extension of $68{ }^{\circ} \mathrm{C}$ for $10 \mathrm{~min}$. PCR products were gel-purified and directly sequenced using primer Xchvssc-F (TSINGKE, Beijing, China).

\section{Sequence analysis}

DNA sequencing data were checked manually. All the confirmed sequences were aligned with MUSCLE 3.8 [17], and nucleotide polymorphisms (SNPs) were documented. Hardy-Weinberg equilibrium (HWE) probability test was conducted using the online software GENEPOP v.4.2 [18]. The VGSC haplotypes were identified by directly reading from homozygotes, or by splitting one from the other from heterozygotes carrying one-site variations. Clone sequencing was conducted for four samples of $1014 \mathrm{~L} / \mathrm{F}$ heterozygotes with multiple-site variations. For clone sequencing, purified PCR products were ligated with the pEasy-T1 vector and transformed into competent cells of the Escherichia coli (DH5a). MEGA 7 [19] and Network v.4.6 [20] were used to analyze the evolutionary origin of the identified haplotypes.

\section{Results}

\section{Detection of $k d r$ mutations}

Sequencing of each amplicon resulted in a clear 369-bp sequence, encompassing two full short introns, a full exon and two partial exons (Fig. 1). Eight nucleotide 


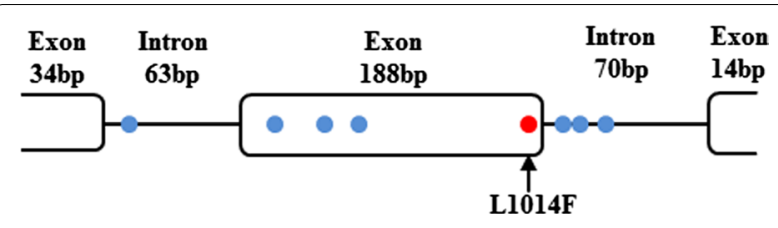

Fig. 1 Schematic representation of the region of Xenopsylla cheopis VGSC gene analyzed in this study. Dots indicate the polymorphic sites in the obtained sequences. The red dot represents the site leading to L1014F mutation

polymorphisms in the 369-bp fragments were observed from a total of 111 individuals. No nucleotide variation was observed in the first and last partial exons. One nonsynonymous mutation, leading to a deduced amino acid substitution of L (CTT) to F (TTT) at the position corresponding to the amino acid residue 1014 of VGSC of the housefly was detected in the second exon, while other three nucleotide polymorphisms in this exon were synonymous. Four polymorphic sites were found in the two introns in total, without length polymorphism being observed (Fig. 1).

The putative partial amino acid sequences (79 amino acids) of $X$. cheopis VGSC (1014L and 1014F) showed high identities with VGSCs of species of the Pulicidae such as the cat flea Ctenocephalides felis (CAG30671.1, 97.44\%) and the human flea Pulex irritans (ANY39518.1, 96.15\%). High similarity of VGSC was also observed between $X$. cheopis with the dipteran Anopheles sinensis
(ABC60026.1, 97.44\%), and the lepidopteran Plutella xylostella (ADH16760.1, 97.44\%) (Fig. 2).

\section{Distribution and frequency of $k d r$ alleles}

Focusing on codon 1014, the three possible genotypes of the $X C$-VGSC gene were observed, and all genotypes were found to agree with Hardy-Weinberg equilibrium (Table 2). The resistant 1014F allele was detected in all of the four populations, with the highest frequency of 0.241 being in Yongle, Youjiang County (YLYJ, Site 1) (Fig. 3). The $k d r$-resistant homozygote was rare and detected only in YLYJ at a low frequency (0.034). The wild-type homozygote was present at high frequencies $(0.552-$ 0.958), while the frequencies of heterozygotes varied from 0.042 to 0.414 .

\section{Genealogical analysis of XC-VGSC haplotypes}

Seven haplotypes (MN103328-MN103334) were identified in this study, with two of them ( $\mathrm{H} 1$ and $\mathrm{H} 2)$ carrying the L1014F mutation (Table 3). The DNA sequences of these haplotypes were used for reconstruction of a phylogenetic tree and for network analysis. The phylogenetic tree revealed that the seven haplotypes are clustered into three groups (Fig. 4). Notably, the two 1014F-carrying haplotypes ( $\mathrm{H} 1$ and $\mathrm{H} 2)$ was grouped into different branches (Group 1 and Group 2, respectively), and their nucleotide sequences differed in both introns and exon (Table 3). The network analysis indicated that $\mathrm{H} 1$ and $\mathrm{H} 2$ were derived from $\mathrm{H} 5$ and $\mathrm{H} 4$, respectively, through only one mutational step (Fig. 5). Sequence analysis showed

$X$ cheopis(1014F) MGMQLFGKNYFDKVDRFPDGDLPRKNFTDFMHSFMIVFRVICGEWIESNWDCMIVGDVSCIPFFIATVVI1014F

$X$. cheopis(1014L) MGMOLFGKNYFDKVDRFPDGDLPRWNFTDFMHSFMTVFRVICGEWIESNWCMIVGDVSCIPFFI VVIGNFVVINL Ctenocephalides felis MGMQLFGKNYYDKVDRF PDGELPRWNFTDFMHSFMIVFRVICGEWIESNWDCMIVGDVSCIPFFIATVVIGNIVVINL Musca domestica MGMQLFGKNYIDHKDRFKDHELPRWNFTDFMHSFMIVFRVLCGEWIESNWDCMYVGDVSCIPFFIATVVIGNIVVINL Pulex irritans MGMQLFGKNYYDKVDRFPDGELPRWNFTDFMHSFMIVFRVICGEWIESNWDCMIVGDVSCIPFFIATVVIGNEVVINL Plutella xylostella MGMQLFGKNYVDHVDRFPDGDLPRWNFTDFMHSFMIVFRVLCGEWIESNWDCMIVGDVSCIPFFIATVVIGNIVVINL Anopheles sinensis MGMQLFGKNYTDNVDRFPDGDIPRWNFTDFMHSFMIVFRVLCGEWIESNWDCMIVGDVSCIPFFIATVVIGNIVVINL

Fig. 2 Multiple alignments of the partial deduced amino acid sequences of the VGSC gene from Xenopsylla cheopis (1014F and 1014L) with corresponding sequences from other species, including Ctenocephalides felis (CAG30671.1), Musca domestica (CAA65448.1), Pulex irritans (ANY39518.1), Plutella xylostella (ADH16760.1) and Anopheles sinensis (ABC60026.1)

Table 2 Frequency of Vgsc genotypes in the four Xenopsylla cheopis populations from Baise of Guangxi, China

\begin{tabular}{|c|c|c|c|c|c|c|}
\hline \multirow[t]{2}{*}{ Site } & \multirow[t]{2}{*}{$n$} & \multicolumn{3}{|c|}{ Frequency } & \multicolumn{2}{|c|}{ HWE probability test } \\
\hline & & $\mathrm{LL}$ & LF & $\mathrm{FF}$ & $P$-value & SE \\
\hline 1 & 29 & 0.552 & 0.414 & 0.034 & 1.0000 & 0.0000 \\
\hline 2 & 28 & 0.857 & 0.143 & & 1.0000 & 0.0000 \\
\hline 3 & 24 & 0.958 & 0.042 & & & \\
\hline 4 & 30 & 0.733 & 0.267 & & 1.0000 & 0.0000 \\
\hline
\end{tabular}




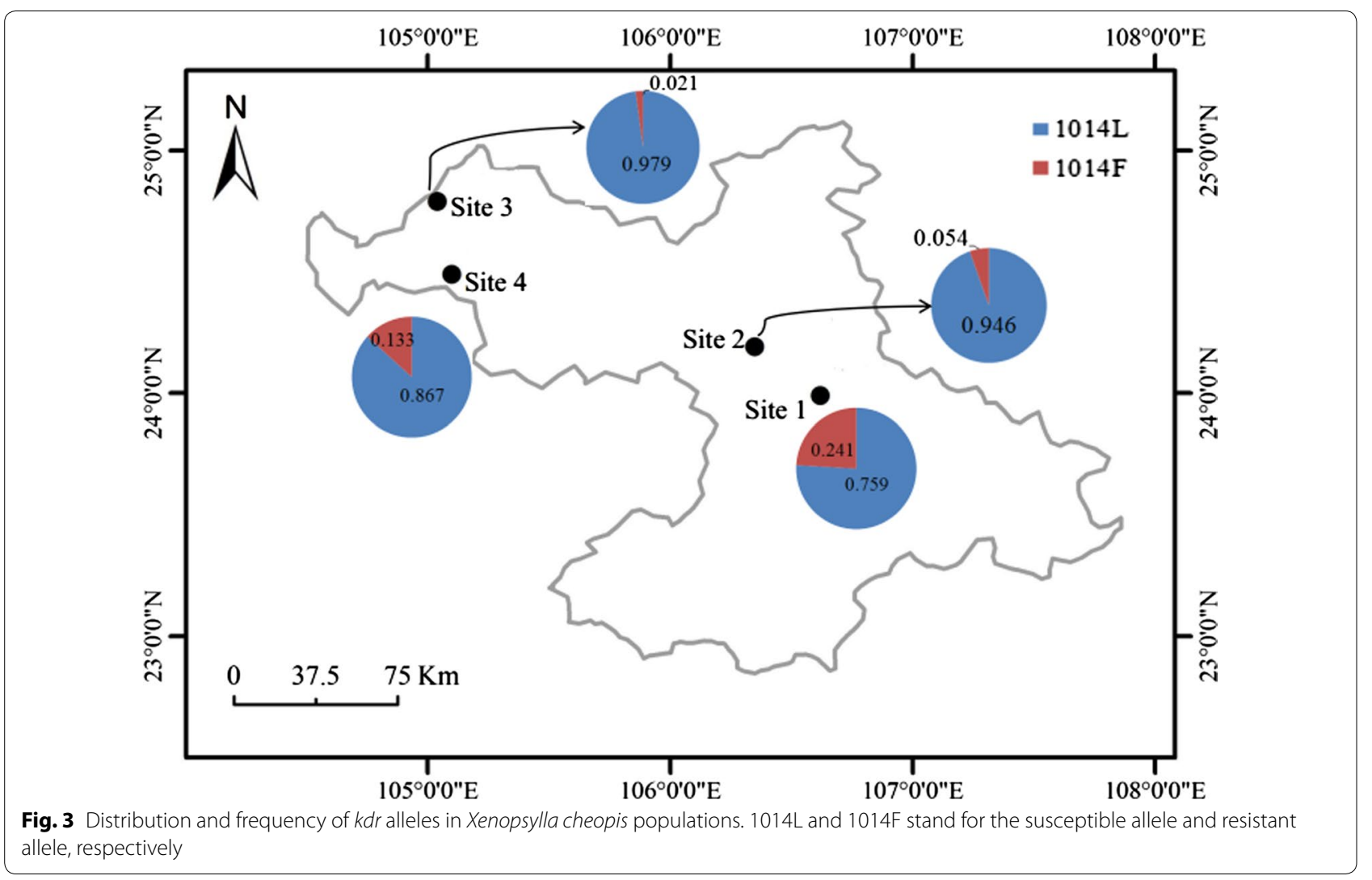

Table 3 Haplotypes of the XC-VGSC gene

\begin{tabular}{llll}
\hline $\begin{array}{l}\text { Haplotype } \\
\text { name }\end{array}$ & $\begin{array}{l}\text { Nucleotide at the } \\
\text { polymorphic sites }\end{array}$ & $\begin{array}{l}\text { Amino acid at } \\
\text { residue 1014 }\end{array}$ & GenBank ID \\
\hline H1 & ICCTTATG & F & MN103328 \\
H2 & GTCTTGGA & F & MN103329 \\
H3 & ITCTCGGA & L & MN103330 \\
H4 & GTCTCGGA & L & MN103331 \\
H5 & ICCTCATG & L & MN103332 \\
H6 & GTTCCATG & L & MN103333 \\
H7 & GTCCCATG & L & MN103334 \\
\hline
\end{tabular}

Note: the polymorphic sites in introns are underlined

that $\mathrm{H} 1$ and $\mathrm{H} 5$ had identical introns, while $\mathrm{H} 2$ shared the same introns with H4 (Table 3).

\section{Establishment of PCR-RFLP assay for genotyping XC-VGSC 1014}

The SNPs at codon 1014 of XC-VGSC generate a MluCI digestion site (Fig. 6a), allowing us to establish a PCRRFLP assay to genotype XC-VGSC 1014. Two primers (Xchvgsc-SF: 5'-GTG GAT CGA GTC TAT GTG GGA$3^{\prime}$, which was designed based on a highly conserved region of DNA sequences, and Xchvgsc-R: 5'-CGA CAA

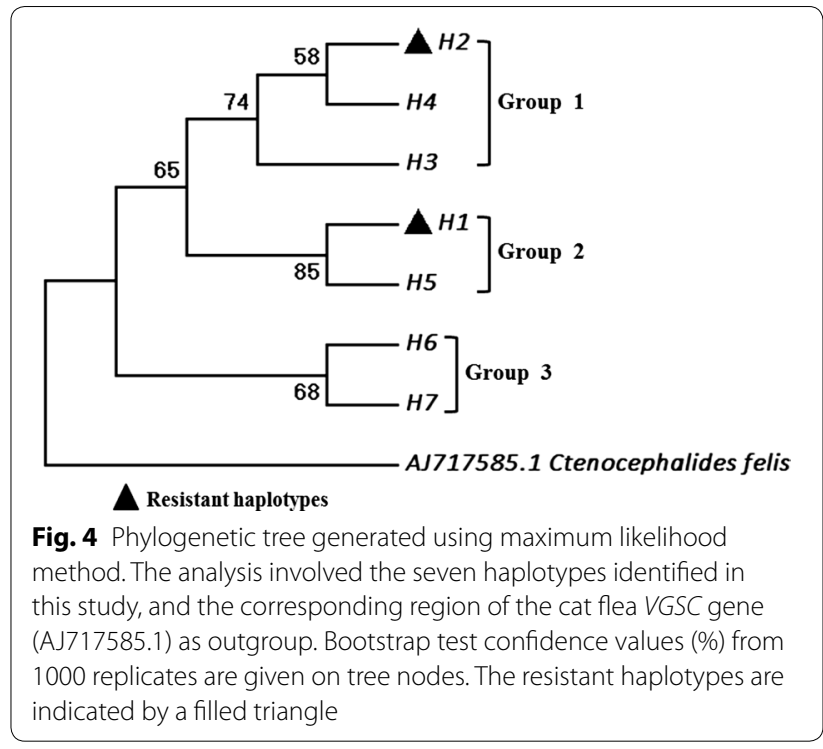

GAG CAA CGC CAA G-3') were used for PCR. The PCR mixture $(25 \mu l)$ contained $2 \times$ EZ4SuperHiFi mix $12.5 \mu \mathrm{l}$; each primer $5 \mu \mathrm{M}, 75-150$ ng DNA template, and $\mathrm{dd}_{2} \mathrm{O}$. PCR conditions were as follows: $95^{\circ} \mathrm{C}$ for 3 min, followed by 42 cycles of $94{ }^{\circ} \mathrm{C}$ for $25 \mathrm{~s} ; 55^{\circ} \mathrm{C}$ for 


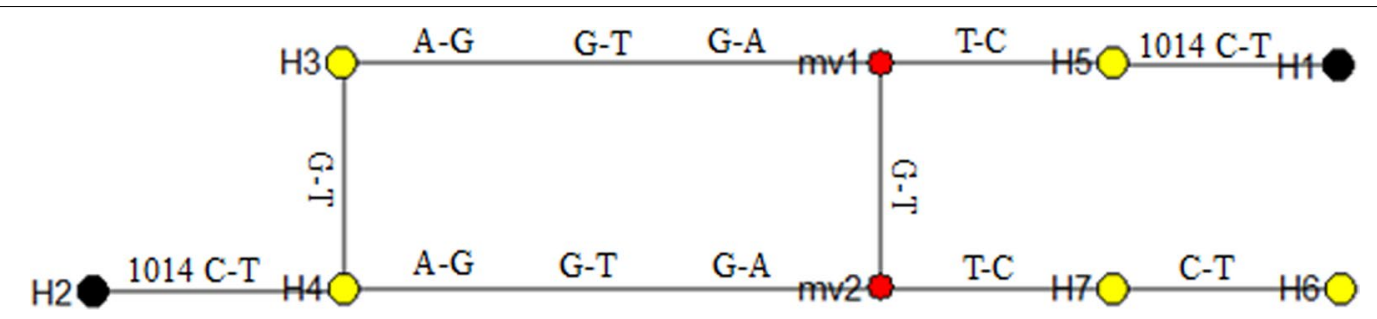

Fig. 5 Genealogical relationship among the seven Xenopsylla cheopis VGSC haplotypes. The base variation between two haplotypes is listed above the line connecting the haplotypes. The resistant haplotype is indicated by a black dot and the susceptible haplotype is marked by a yellow dot. The median vectors ( $\mathrm{mv} 1$ and $\mathrm{mv} 2$, red dot) are hypothesised sequences required to connect existing sequences within the network with maximum parsimony
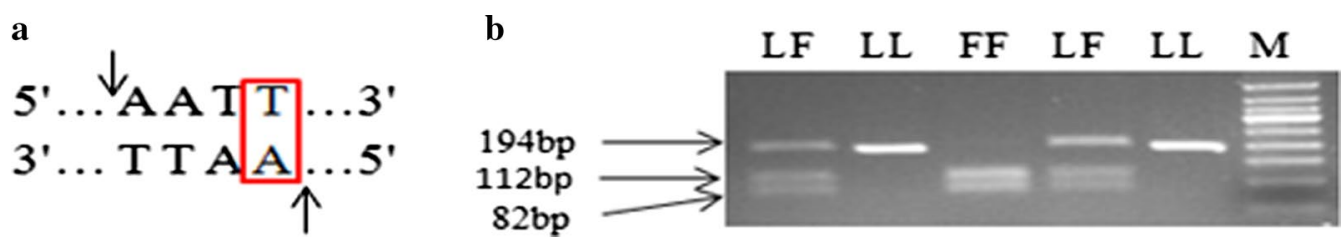

Fig. 6 PCR-RFLP assay for XC-VGSC 1014 genotyping. a The digestion site of enzyme MluCI. The first nucleotide of codon 1014 of the $1014 \mathrm{~F}$ allele is boxed. $\mathbf{b}$ Electrophoresis detection of restriction endonuclease digestion product. Lane M: DNA marker; L: 1014L; F: 1014F

$25 \mathrm{~s}$ and $68^{\circ} \mathrm{C}$ for $30 \mathrm{~s}$, and a final extension at $68^{\circ} \mathrm{C}$ for $10 \mathrm{~min}$. The digestion reactions contained $0.5 \mathrm{U}$ of $\mathrm{MluCI}$ (New England Biolabs, Beijing, China), $2 \mu \mathrm{l}$ of cutsmart buffer, $8 \mu \mathrm{l}$ of PCR product, and $\mathrm{dd}_{2} \mathrm{O}$ up to $20 \mu \mathrm{l}$. The digestion mixture was incubated at $37{ }^{\circ} \mathrm{C}$ for $3 \mathrm{~h}$, and the digested products were run on $3 \%$ gel and visualized under UV. The genotypes were identified based on the presence or absence of cleaved bands. For 1014L alleles, there is no restriction site for MluCI, only a 194-bp band was present on the gel. MluCI was able to cut $1014 \mathrm{~F}$ allele, giving two cleaved fragments of $112 \mathrm{bp}$ and $82 \mathrm{bp}$. The RFLP profiles for the three possible genotypes are shown in Fig. 6b.

Direct sequencing of the PCR products was performed to validate the PCR-RFLP genotyping results. PCR-RFLP gave unambiguous scoring of all genotypes that were $100 \%$ in agreement with direct sequencing in a total of sixty individuals (10 from Sites 2-4, respectively, and 30 from Site 1).

\section{Discussion}

Pyrethroids are widely and often used to control disease vectors. Following the continuous use of various pyrethroids, resistance has been documented in many insects [12]. A major mechanism of pyrethroid resistance, which is caused by point mutations in the voltage gated sodium channel, has been well recognized. The common L1014F mutation, originally found in Musca domestica and referred to as $k d r$ mutation [13], has been detected in a wide variety of insect species [12], including the cat flea (C. felis) [14] and human flea (P. irritans) [15]. In this survey, the presence of the L1014F mutation was observed in all the four tested $X$. cheopis populations collected in Baise of Guangxi Province. To our knowledge, this represents the first detection of the classical $k d r$ mutation (L1014F) in this plague vector.

The levels of resistance conferred by the L1014F mutation have been documented variable, ranging from 12 (fenpropathrin) to 260 (etofenprox) in the house fly [21]. The overall low frequency of the L1014F allele indicates that the $k d r$ mechanism seems unlikely to cause failure of oriental rat flea control in this region. However, as a limitation of this study, the lack of susceptibility information for the samples tested in this study makes it risky to predict the status of insecticide resistance in these oriental rat flea populations. Additionally, it is unknown whether other factors such as increased detoxification of insecticides contribute to resistance. Therefore, further investigations are required to clarify this issue. The relatively high frequency (0.241) of the L1014F mutation (Fig. 3) and the occurrence of resistant homozygote (1014FF) in the YLYJ population (Table 2) calls for close monitoring and surveillance of pyrethroid susceptibility in this area.

Two different haplotypes that carry the L1014F mutation ( $\mathrm{H} 1$ and $\mathrm{H} 2$ ) were identified (Table 3). Among the eight polymorphic sites, five were different between $\mathrm{H} 1$ and H2. Further phylogenetic and network analysis strongly suggest that $\mathrm{H} 1$ and $\mathrm{H} 2$ have independent 
origins (Figs. 4, 5). The two resistant haplotypes (H1 and $\mathrm{H} 2$ ) could be derived from wild $\mathrm{H} 5$ and $\mathrm{H} 4$ with one mutational step respectively. Multiple origins of insecticide resistance conferring point mutations in the voltagegated sodium channel gene have also been characterized in several other insect species [17, 22-25].

Early detection and monitoring of insecticide resistance in a vector population may provide evidence-based implications for making vector intervention strategies. In this context, we have developed a simple PCR-RFLP assay that can be used to accurately genotype individual fleas for the resistance-conferring L1014F mutation (Fig. 6b).

\section{Conclusions}

The classical $k d r$ mutation (L1014F) was detected in $X$. cheopis field populations collected from Guangxi Province of China at frequencies of 0.021-0.241. Two different haplotypes carrying the L1014F mutation were identified. Phylogenetic tree and network analysis suggested that the L1014F allele was not singly originated. A simple, rapid and accurate molecular assay for screening individual fleas for the L1014F mutation was developed.

\section{Abbreviations \\ Kdr: knockdown resistance; PCR: polymerase chain reaction; RFLP: restriction fragment length polymorphism; VGSC: voltage gated sodium channel.}

\section{Acknowledgments}

We are grateful to Baise CDC of Guangxi China for assistance with sample collection. We would thank the anonymous reviewers and editors for their comments and edits.

\section{Authors' contributions}

XHQ and XYF conceived and designed the experiments. NL and ML performed the experiments. QXH and NL analyzed the data. XYF contributed flea specimens. QXH, NL and XYF wrote the paper. All authors read and approved the final manuscript.

\section{Funding}

This work was supported by the State Key Laboratory of Integrated Management of Pest Insects and Rodents. The funders had no role in the study design, data collection, analysis, decision to publish or preparation of the manuscript.

\section{Availability of data and materials}

Data supporting the conclusions of this article are provided within the article. The newly generated sequences were submitted to the GenBank database under the accession numbers MN103328-MN103334.

Ethics approval and consent to participate

Not applicable.

\section{Consent for publication}

Not applicable.

\section{Competing interests}

The authors declare that they have no competing interests.

\footnotetext{
Author details

${ }^{1}$ State Key Laboratory of Integrated Management of Pest Insects and Rodents, Institute of Zoology, Chinese Academy of Sciences, Beijing 100101, China.

${ }^{2}$ Guangxi Zhuang Autonomous Region Center for Diseases Control and Prevention, Nanning 530028, China.
}

Received: 22 July 2019 Accepted: 25 October 2019

Published online: 06 November 2019

\section{References}

1. Bertherat E. Plague around the world, 2010-2015. Wkly Epidemiol Rec. 2016;91:89-93.

2. https://www.who.int/en/news-room/fact-sheets/detail/plague.

3. Boyer S, Miarinjara A, Elissa N. Xenopsylla cheopis (Siphonaptera: Pulicidae) susceptibility to deltamethrin in Madagascar. PLoS ONE. 2014;9:e111998.

4. Wang X, Wei X, Song Z, Wang M, Xi J, Liang J, et al. Mechanism study on a plaque outbreak driven by the construction of a large reservoir in southwest China (surveillance from 2000-2015). PLoS Negl Trop Dis. 2017;11:e0005425.

5. Zhao F, Zhang T, Su J, Huang Z, Wu A, Lin G. Genetic differentiation of the oriental rat flea, Xenopsylla cheopis, from two sympatric host species. Parasites Vectors. 2018:11:343.

6. Liang J, Liu Z, Zeng J, Jiang C, Zhou S, et al. Investigation on the plague foci in Baise reservior region in Guangxi Province. Foreign Med Sci (Medgeograp). 2011;32:196-214.

7. Feng X, Yang G, Huang J, Yang J, Ni E, Cao P. Investigation of species of the major host animals and the major vectors during outbreak of plague in Longlin county, Guangxi. Chin J Vector Biol Control. 2004;15:51-3.

8. Nong Z, Cen Y, Yu S, Lu X, Deng J, Huang R. Analysis of plague hosts and vector monitoring results in Baise City in 2010-2014. J Trop Med. 2017;17:266-8

9. Nong Z, Yu S, Lu X, Feng X, Deng J, Tian H, et al. Study on the drug resistance of Xenopsylla cheopis to pyrethroids. Chin J Vector Biol Control. 2019;30:112-4.

10. Miarinjara A, Boyer S. Current perspectives on plague vector control in Madagascar: susceptibility status of Xenopsylla cheopis to 12 insecticides. PLoS Negl Trop Dis. 2016;10:e0004414

11. Miarinjara A, Vergain J, Kavaruganda JM, Rajerison M, Boyer S. Plague risk in vulnerable community: assessment of Xenopsylla cheopis susceptibility to insecticides in Malagasy prisons. Infect Dis Poverty. 2017;6:141.

12. Dong K, Du Y, Rinkevich F. Molecular biology of insect sodium channels and pyrethroid resistance. Insect Biochem Mol Biol. 2014;50:1-17.

13. Williamson MS, Martinez-Torres D, Hick CA. Identification of mutations in the housefly para-type sodium channel gene associated with knockdown resistance (kdr) to pyrethroid insecticides. Mol Gen Genet. 1996;252:51-60.

14. Bass C, Schroeder I, Turberg A, Field LM, Williamson MS. Identification of mutations associated with pyrethroid resistance in the para-type sodium channel of the cat flea, Ctenocephalides felis. Insect Biochem Mol Biol. 2004;334:1305-13.

15. Ghavami MB, Haghi FP, Alibabaei Z, Enayati AA, Vatandoost H. First report of target site insensitivity to pyrethroids in human flea, Pulex irritans (Siphonaptera: Pulicidae). Pestic Biochem Physiol. 2018;146:97-105.

16. Rinkevich FD, Zhang L, Hamm RL, Brady SG, Lazzaro B, Scott JG. Frequencies of the pyrethroid resistance alleles of VsSC1 and CYP6D1 in house flies from the eastern United States. Insect Mol Biol. 2006;15:157-67.

17. Edgar RC. MUSCLE: multiple sequence alignment with high accuracy and high throughput. Nucl Acids Res. 2004;32:1792-7.

18. Rousset F. Genepop'007: a complete reimplementation of the Genepop software for Windows and Linux. Mol Ecol Resour. 2008;8:103-6.

19. Kumar S, Stecher G, Tamura K. MEGA7: molecular evolutionary genetics analysis version 7.0 for bigger datasets. Mol Biol Evol. 2016;33:1870-4.

20. Bandelt $H$, Forster $P$, Rohl A. Median-joining networks for inferring intraspecific phylogenies. Mol Biol Evol. 1999;16:37-48.

21. Sun H, Tong KP, Kasai S, Scott JG. Overcoming super-knock down resistance (super-kdr) mediated resistance: multi-halogenated benzyl pyrethroids are more toxic to super-kdr than $k d r$ house flies. Insect Mol Biol. 2016;25:126-37.

22. Pinto J, Lynd A, Vicente JL, Santolamazza F, Randle NP, Gentile G, et al. Multiple origins of knockdown resistance mutations in the afrotropical mosquito vector Anopheles gambiae. PLoS ONE. 2007;2:e1243.

23. Rinkevich FD, Hedtke SM, Leichter CA, Harris SA, Su C, Brady SG, et al. Multiple origins of $k d r$-type resistance in the house fly Musca domestica. PLoS ONE. 2012;7:e52761. 
24. Dang K, Toi CS, Lilly DG, Lee C-Y, Naylor R, Tawatsin A, et al. Identification of putative $k d r$ mutations in the tropical bed bug, Cimex hemipterus (Hemiptera: Cimicidae). Pest Manag Sci. 2015;71:1015-20.

25. Yang C, Feng X, Huang Z, Li M, Qiu X. Diversity and frequency of $k d r$ mutations within Anopheles sinensis populations from Guangxi, China. Malar J. 2016;15:411.

\section{Publisher's Note}

Springer Nature remains neutral with regard to jurisdictional claims in published maps and institutional affiliations.
Ready to submit your research? Choose BMC and benefit from:

- fast, convenient online submission

- thorough peer review by experienced researchers in your field

- rapid publication on acceptance

- support for research data, including large and complex data types

- gold Open Access which fosters wider collaboration and increased citations

- maximum visibility for your research: over $100 \mathrm{M}$ website views per year

At BMC, research is always in progress.

Learn more biomedcentral.com/submissions 